
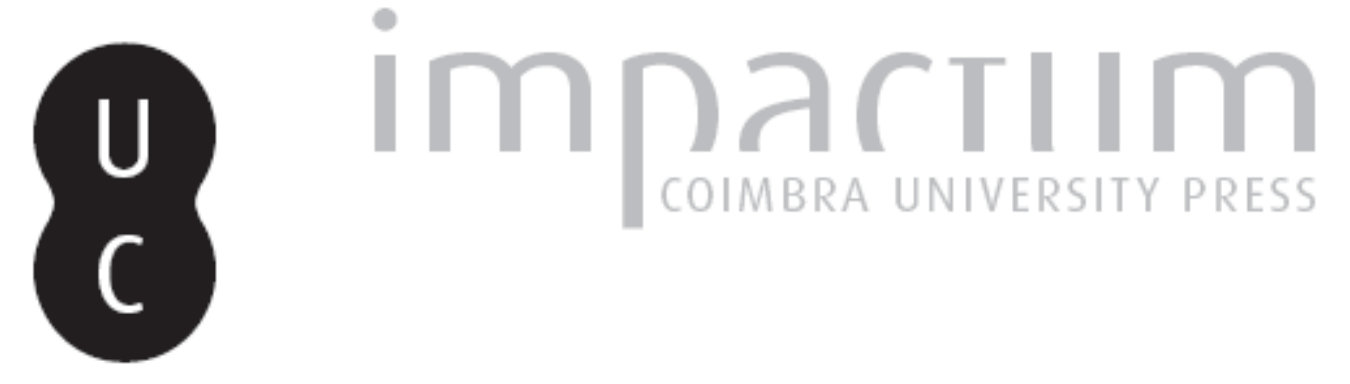

\title{
"Educação para o risco": conhecimento e contribuição de professores de Geografia para o tema risco ambiental em escolas de Minas Gerais - Brasil
}

Autor(es): $\quad$ Souza, Carla Juscélia de Oliveira; Silva, Veridiane Meire da

Publicado por: Imprensa da Universidade de Coimbra

URL

persistente:

URI:http://hdl.handle.net/10316.2/44193

DOI:

DOI:https://doi.org/10.14195/1647-7723_25-2_5

Accessed : $\quad$ 26-Apr-2023 01:07:29

A navegação consulta e descarregamento dos títulos inseridos nas Bibliotecas Digitais UC Digitalis, UC Pombalina e UC Impactum, pressupõem a aceitação plena e sem reservas dos Termos e Condições de Uso destas Bibliotecas Digitais, disponíveis em https://digitalis.uc.pt/pt-pt/termos.

Conforme exposto nos referidos Termos e Condições de Uso, o descarregamento de títulos de acesso restrito requer uma licença válida de autorização devendo o utilizador aceder ao(s) documento(s) a partir de um endereço de IP da instituição detentora da supramencionada licença.

Ao utilizador é apenas permitido o descarregamento para uso pessoal, pelo que o emprego do(s) título(s) descarregado(s) para outro fim, designadamente comercial, carece de autorização do respetivo autor ou editor da obra.

Na medida em que todas as obras da UC Digitalis se encontram protegidas pelo Código do Direito de Autor e Direitos Conexos e demais legislação aplicável, toda a cópia, parcial ou total, deste documento, nos casos em que é legalmente admitida, deverá conter ou fazer-se acompanhar por este aviso.

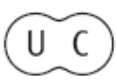




\title{
“EDUCAÇÃO PARA O RISCO”: CONHECIMENTO E CONTRIBUIÇÃO DE PROFESSORES DE GEOGRAFIA PARA O TEMA RISCO AMBIENTAL EM ESCOLAS DE MINAS GERAIS - BRASIL*
}

\author{
"RISK EDUCATION": KNOWLEDGE AND CONTRIBUTION OF GEOGRAPHY TEACHERS TO THE TOPIC OF \\ ENVIRONMENTAL RISK IN MINAS GERAIS SCHOOLS, BRAZIL
}

Carla Juscélia de Oliveira Souza Departamento de Geociências da Universidade Federal de São João del-Rei (Brasil) ORCID 0000-0002-1426-4790 carlaju@ufsj.edu.br

Veridiane Meire da Silva

Rede Estadual de Ensino de Minas Gerais (Brasil) ORCID 0000-0002-9942-1432 verigeografiaufsj@yahoo.com.br

\begin{abstract}
RESUMO
Pensar a "Educação para o Risco" leva a pensar, também, nos conhecimentos que os professores têm a respeito do tema. Com base nessa ideia, uma pesquisa que investiga o conhecimento e o saber disciplinar entre professores de Geografia do estado de Minas Gerais - Brasil, referente à temática risco ambiental e suas práticas em sala de aula, vem sendo desenvolvida desde 2015. A pesquisa foi motivada pelas questões: "Os professores de Geografia conhecem o significado do termo Risco ambiental e reconhecem em sua região, ou cidade, áreas de risco ambiental?" e "Esse assunto é trabalhado nas aulas de geografia?". O levantamento de dados e informações foi realizado por meio de questionário contendo trinta e sete questões, disponibilizado google Drive para professores egressos entre os anos de 2011 e 2015. Os resultados indicam que entre os professores, que participaram do estudo, ainda são poucos os que conhecem bem o assunto e trabalham a temática riscos ambientais nas aulas de geografia.
\end{abstract}

Palavras-chave: Concepção de risco ambiental, ensino de geografia, degradação ambiental.

\section{ABSTRACT}

Thinking about "Risk Education' also leads us to think about what teachers know about the topic. Based on this idea, a study that looks at the knowledge of geography professors in the state of Minas Gerais, Brazil, with respect to environmental risk, and their classroom practice, has been under way since 2015. The research was motivated by the questions: "Do geography teachers know the meaning of the term environmental risk and recognize areas of environmental risk in their region or city?"; "Is this subject studied in geography classes?" The data and qualitative information were collected through a questionnaire containing thirty-seven questions, made available on the google Drive platform for teachers graduating between 2011 and 2015. The results indicate that among the teachers who participated in the study, there are still few who know the subject well and work on environmental risks in geography classes.

Keywords: Concept of environmental risk, geography teaching, environmental degradation.

\footnotetext{
* O texto deste artigo corresponde a uma comunicação apresentada no IV Congresso Internacional de Riscos, tendo sido submetido em 13-09-2017, sujeito a revisão por pares a 25-10-2017 e aceite para publicação em 28-12-2017. Este artigo é parte integrante da Revista Territorium, $n .{ }^{\circ} 25$ (II), 2018, ${ }^{\circ}$ RIscos, ISSN: 0872-8941.
} 


\section{Introdução}

A "Educação para o risco" é reconhecida em várias partes do mundo como componente essencial na formação de jovens que podem estar ou não expostos a riscos de diferente natureza. Em Portugal, o Conselho Nacional de Educação, através da recomendação n. ${ }^{\circ}$ /2011, coloca que as escolas devem promover a "Educação para o risco", acrescentando em seus currículos conteúdos referentes aos diferentes conceito de risco, além de ações que lidam na prática com riscos específicos (CNE, 2011). A Redução de Risco de Desastres (RRD) é também uma ideia e um movimento mundial. Dezenas de países já adotam a ideia RRD, por meio da Educação na escola básica.

Em 2011, trinta países tiveram seus currículos estudados pela UNESCO e UNICEF, com atenção para os aspectos conteúdos, metodologias, práticas e pedagogias adotados no processo de formação de crianças e jovens da educação básica, com o objetivo de integração da RRD (Souza, 2014a; Silva, 2017). Os estudos da UNESCO e UNICEF objetivaram levantar as experiências e práticas bem sucedidas entre países da Europa Central e Oriental, Leste da Ásia e Pacífico, África Oriental e Austral, América Latina (Selby e Kagawa, 2012) e outras partes do mundo.

A ideia e as ações para a Redução de Risco de Desastres, promovidas em diversos países, buscam o crescimento da conscientização sobre os desastres, sobre os fenômenos naturais e a promoção da cultura de prevenção, principalmente entre a população que apresenta maior vulnerabilidade a riscos e desastres. Cerca de $75 \%$ da população mundial reside em áreas que foram afetadas, pelo menos uma vez, por um evento natural catastrófico, no período entre 1980 e 2000, conforme a UNDP (2004) citada por Nunes et al. (2009).

As pesquisas e ações no Brasil na área da Redução de Risco de Desastres (RRD) e "Educação para o Risco" ainda são tímidas e quase ausentes, quando relacionadas ao âmbito escolar, apesar de existir a Lei $n^{\circ} 12.608$, de 10 de abril de 2012, que institui a Política Nacional de Proteção e Defesa Civil (Brasil, 2012). Esta afirma em seu Art. 29 que o artigo 26 da Lei no 9.394, de 20 de dezembro de 1996, que estabelece as diretrizes e bases da educação nacional, passa a vigorar acrescido do Parágrafo $7^{\circ}$ "Os currículos do ensino fundamental $e$ médio devem incluir os princípios da proteção e defesa civil e a educação ambiental de forma integrada aos conteúdos obrigatórios". Geralmente, as ações para prevenção acontecem em comunidades que já sofreram algum tipo de desastre resultante de fenômeno natural combinado com o social, como ocorreu no município de Nova Friburgo, no estado do Rio de Janeiro.

Depois da tragédia ocorrida na região serrana do Rio de Janeiro entre 11 e 12 de janeiro 2011, na qual ocorreram 916 vítimas fatais - de enchentes, deslizamentos e desabamentos
- milhares desabrigados e centenas desaparecidos, o governo federal lançou em 2012 o Plano Nacional de Gestão de Riscos e Resposta aos Desastres Naturais (Allen, 2012). O objetivo do plano é garantir segurança às populações que vivem em áreas suscetíveis a ocorrências de eventos naturais danosos e as ações preventivas visam, também, preservar o meio ambiente e abranger 821 municípios que respondem por $94 \%$ das mortes e $88 \%$ do total de desalojados e desabrigados em todo país (PAC, 2012).

Esse plano contempla medidas de prevenção que compreendem definição de obras necessárias, mapeamento de áreas de riscos, monitoramento/alerta em rede nacional e respostas por meio de assistência e reconstrução. Mas, não indica a "Educação para o risco" no âmbito da educação básica, ou seja nas escolas de ensino fundamental e médio. Em 2014, o CEMADEN Centro Nacional de Monitoramento e alertas de desastres naturais - lançou o projeto Cemaden Educação voltado para as escolas da educação básica brasileira, com o objetivo de contribuir para a geração de uma cultura da percepção de riscos de desastres, no amplo contexto da educação ambiental e da construção de sociedades sustentáveis e resilientes (CEMADEN, 2016).

Em várias cidades brasileiras ocorre o aumento de desastres decorrentes de eventos danosos, favorecidos pelo aumento populacional nas cidades, pela condição de vulnerabilidade de parte dessa população, combinados com outros fatores. A realidade do aumento populacional e de ocorrência de desastres não é diferente no estado de Minas Gerais. De acordo com o Censo 2010, a população urbana brasileira correspondia à $84,4 \%$, enquanto em Minas Gerais o valor era de 85,3\% em 2010, último censo disponibilizado ao público.

Geralmente, quando se discute a respeito de desastres, áreas de riscos ambientais, combates e prevenção aos riscos, são os profissionais da Defesa Civil, da área das geotécnicas, assim como Corpo de Bombeiro e outros profissionais envolvidos em ações diretas de socorro e prevenções que a fazem. Mas, e a escola? E a geografia escolar? (Souza e Oliveira, 2011). A escola, como espaço de formação social e básica para a cidadania e a Geografia como conhecimento referente ao espaço geográfico, têm contribuído ou participado dessas discussões? Não caberiam aos professores de Geografia trabalhar e discutir, também, temas ligados às questões sociais/urbanas, sociais/rurais como “áreas de risco ambiental”, como processo de construção de conhecimento e de prevenção aos processos perigosos e aos desastres comuns nas cidades? (Souza, 2013a, 2013b, 2014b). Essas indagações apresentadas por Souza e Oliveira (2011) em alguns de seus trabalhos, instigam o interesse por estudar cada vez mais os conhecimentos e as práticas de professores de geografia e de crianças e jovens escolares, com o propósito de se conhecer o entendimento que professores 
e alunos apresentam sobre o tema. E, também, promove o interesse por conhecer a realidade da temática riscos e riscos ambientais entre os conteúdos de geografia e as práticas escolares existentes em escolas mineiras.

O professor concebido como um intelectual (Giroux, 2009) tem papel fundamental na formação de opinião, conhecimento e ações individuais e coletivas. Portanto, o professor de geografia como intelectual público, como profissional professor que trabalha e discute no ensino de geografia a relação Sociedade e Natureza, pode e deve se apropriar da discussão sobre riscos, em específico os riscos ambientais e trabalha-los com os alunos do ensino fundamental e médio. Portanto, constituiu premissa da pesquisa, em andamento, conhecer os saberes e as experiências dos professores, para que se possa, então, discutir o tema risco ambiental e, assim, em momento posterior propor conteúdos e conceitos a serem construídos junto aos alunos da educação básica, adotando como referência os saberes desses professores e os das ciências cindínicas, também identificadas como "ciências do risco"/"ciências do perigo", conforme designado por Rebelo (2001).
A pesquisa em questão é desenvolvida por meio de diversos subprojetos (mestrado e iniciação científica) relacionados a um projeto maior aprovado pelo Conselho Nacional de Desenvolvimento Científico e Tecnológico - CNPq, via o edital Universal MCTI/CNPQ/Universal 14/2014 (Souza, 2014a). A investigação tem como objetivo geral pesquisar o conhecimento e a prática de professores de Geografia de Minas Gerais sobre o tema riscos ambientais e áreas de risco, atenta aos objetivos específicos: verificar entre os professores de Geografia a concepção de risco ambiental; levantar junto aos professores de Geografia quando, como e o que é abordado sobre risco ambiental durante as aulas de Geografia e levantar a percepção dos professores sobre a existência de áreas de risco ambiental em seu município de atuação profissional, entre outros objetivos que não serão contemplados neste texto.

A pesquisa contou com a participação de oitenta e nove professores residentes em diversos municípios mineiros, distribuídos em nove das doze mesorregiões do estado de Minas Gerais (fig. 1), classificadas pelo Instituto Brasileiro de Geografia e Estatística (IBGE).

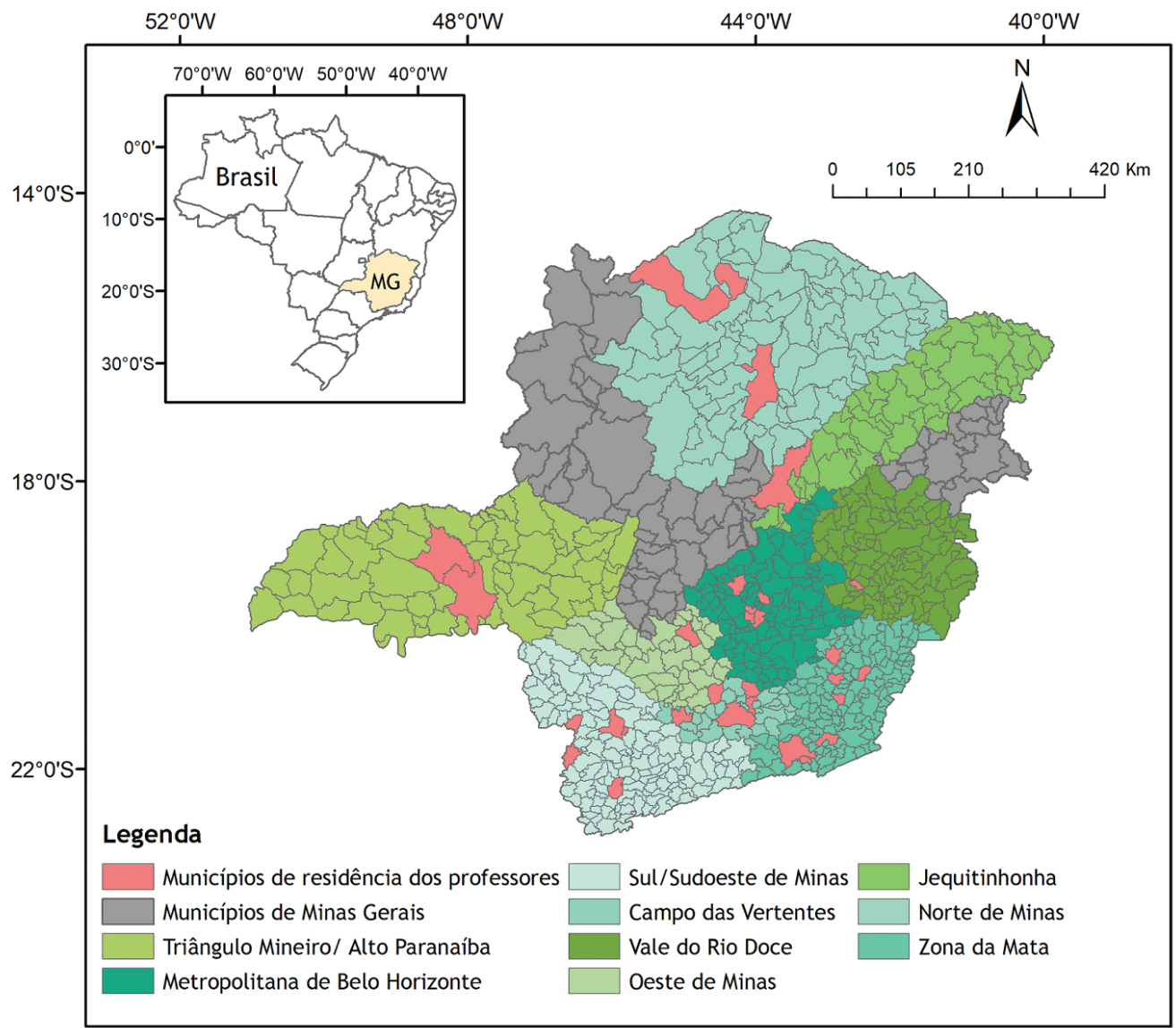

Fig. 1 - Distribuição geográfica dos munícipios dos professores participantes da pesquisa por mesorregiões mineiras (Fonte: Dados da pesquisa, 2017).

Fig. 1 - Geographical distribution of the municipalities of the teachers participating in the research, by mesoregions of Minas Gerais (Source: Research data, 2017). 
Neste texto são apresentados e discutidos os resultados alcançados com a pesquisa intitulada "Educação para o risco: conhecimento e contribuição de professores de geografia para o tema risco ambiental em escolas de Minas Gerais”, a qual dá título ao presente texto, organizado em três partes.

A primeira parte traz o percurso metodológico da pesquisa com algumas observações e comentários à respeito do procedimento escolhido. Na segunda, alguns conceitos e noções considerados como fundamento teórico são apresentados de maneira objetiva, mas que contribuem para o leitor conhecer o entendimento da concepção de risco ambiental e risco natural entre alguns autores e a concepção adotada na pesquisa. Estes referenciais ajudam a analisar a concepção e o conhecimento apresentados pelos professores de geografia, discutidos na terceira parte deste trabalho.

\section{Procedimento metodológico e a escolha dos profes- sores mineiros}

\section{Localização dos professores em Minas Gerais}

Os professores de Minas Gerais foram os escolhidos como participantes da pesquisa devido ao fato de Minas Gerais ser um estado que congrega importantes universidades federais e universidade estadual com cursos de formação de professores de Geografia; por ser o estado de origem, residência e interesse das pesquisadoras; pela possibilidade de maior acesso as mesorregiões mineiras, ainda que seja um estado grande, e a crença na facilidade de acesso ao banco de dado das universidades, sobre os professores de geografia egressos no período de 2011 a 2015.

Portanto, para o estudo foram contatadas dez universidades mineiras (fig. 2) - Universidade Federal do Vale do Jequitinhonha e Mucuri (UFVJM), Universidade Federal do Triângulo Mineiro (UFTM), Universidade Federal de Uberlândia (UFU), Universidade Federal de Viçosa (UFV), Universidade Federal de São João del-Rei (UFSJ), Universidade Federal de Juiz de Fora (UFJF), Universidade Federal de Lavras (UFLA), Universidade Federal de Alfenas (UNIFAL), Universidade Federal de Ouro Preto (UFOP), Universidade Federal de Minas Gerais (UFMG), Universidade Estadual de Montes Claros (UNIMONTES).

Das dez universidades contatadas, via documento emitido pelo Programa de Pós-Graduação em Geografia (PPGeog), somente oito concordaram em fornecer o e-mail de contato de seus ex-alunos, residentes em diversos municípios mineiros e em outros estados São Paulo e Rio de Janeiro. 0 total de e-mails válidos disponibilizados pelas universidades somaram 507, dos quais 89 foram respondidos pelos professores de

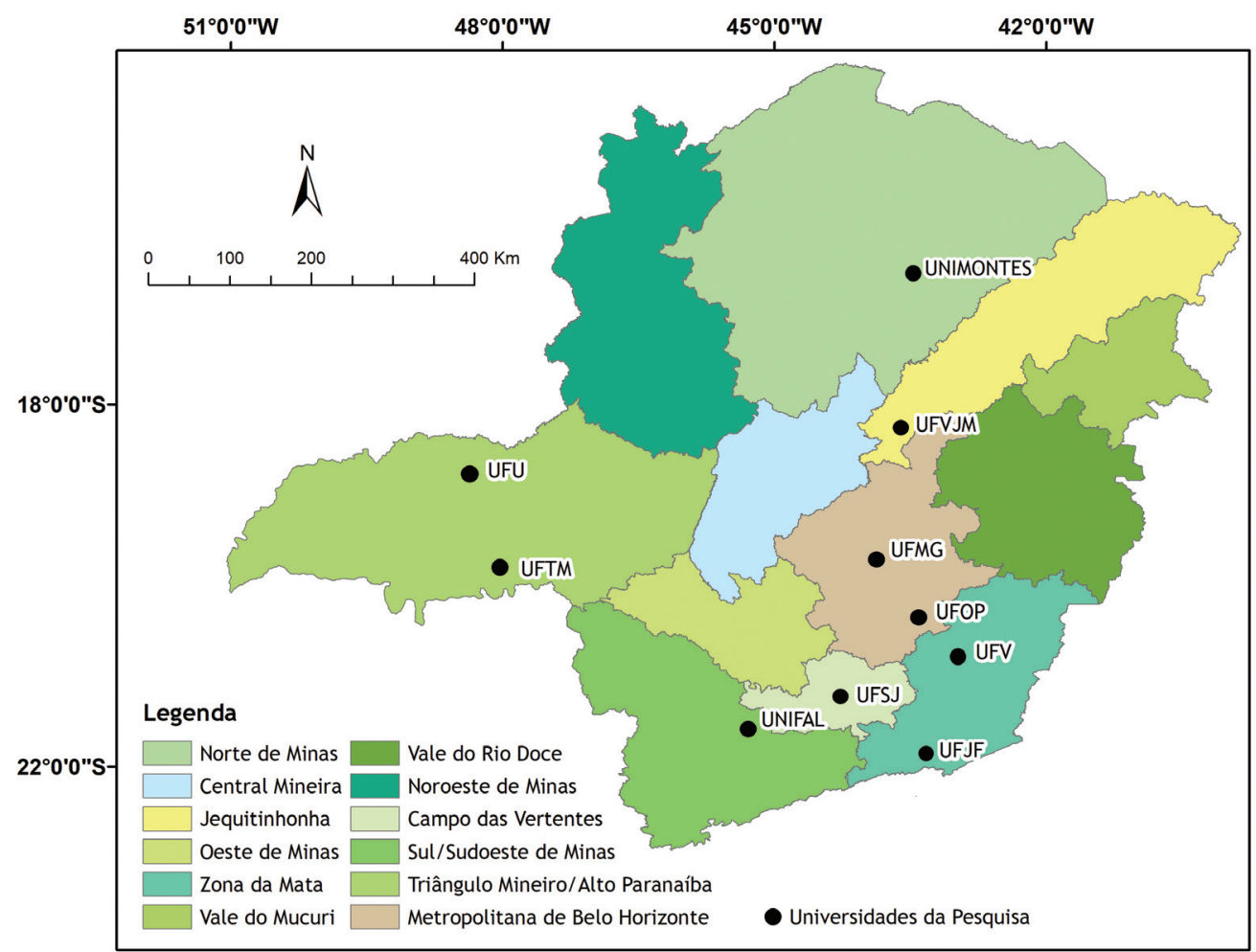

Fig. 2 - Distribuição geográfica das Universidades Federais contatadas, por mesorregiões mineiras (Fonte: Silva, 2017).

Fig. 2 - Geographical distribution of Federal Universities contacted, by mesoregions of Minas Gerais (Source: Silva, 2017). 
Geografia (QUADRo I). Esses professores foram convidados a responderem um questionário online, elaborado com o recurso do google drive e disponibilizado apenas para os participantes. Estes responderam à trinta e sete questões, organizadas em três partes compostas por questões abertas e fechadas, as quais constituíram o principal instrumento de coleta e registro de dados e informações qualitativas da referida pesquisa.

Instrumento de coleta de dados e informações: questionário online

A primeira parte do questionário contemplou Informações gerais sobre os professores, as quais permitiram conhecer a localização, a faixa etária, a instituição de formação, a situação profissional atual, entre outros aspectos dos participantes da pesquisa. A segunda considerou a abordagem teórico-conceitual, a partir da qual foi possível levantar entre os professores o conhecimento e a concepção de risco e risco ambiental dos mesmos. A terceira parte permitiu levantar como e quando os professores trabalham com o tema na sala de aula e, ainda, verificar informações referentes à formação inicial em Geografia dos professores participantes.

Inicialmente, esperava-se trabalhar com um número maior de pessoas. Porém, devido às barreiras enfrentadas - recusa de algumas universidades em colaborar e a ausência de respostas aos e-mails e convites enviados por diversas vezes sem sucesso - optou-se por dar continuidade ao trabalho com o número obtido (89) e mais tarde buscar novos caminhos para localizar professores egressos dos cursos de geografia, via rede social (facebook) e contatos pessoais. Neste trabalho são apresentados e discutidos os resultados alcançados com as respostas dos oitenta e nove professores mineiros (fig.1).
A distribuição geográfica desses professores acompanha bastante a distribuição das universidades federais e estadual em Minas Gerais, com cursos de Geografia, reforçando a importância da descentralização das universidades da capital e dos grandes e médios centros urbanos, que ocorreu a partir dos anos de 2000. Essa descentralização ocorreu com o programa REUNI Restruturação e Expansão das Universidades Federais - realizado durante o governo do Presidente Luís Inácio Lula da Silva. A porção centro e sul do estado de Minas Gerais, onde ocorre maior densidade demográfica em Minas Gerais, (fig. 3) concentra, também, o maior número de universidades públicas, conforme pode-se observar nas fig.s 2 e 3 .

As respostas quantitativas obtidas com os questionários foram tratadas em planilha Excel, representadas em

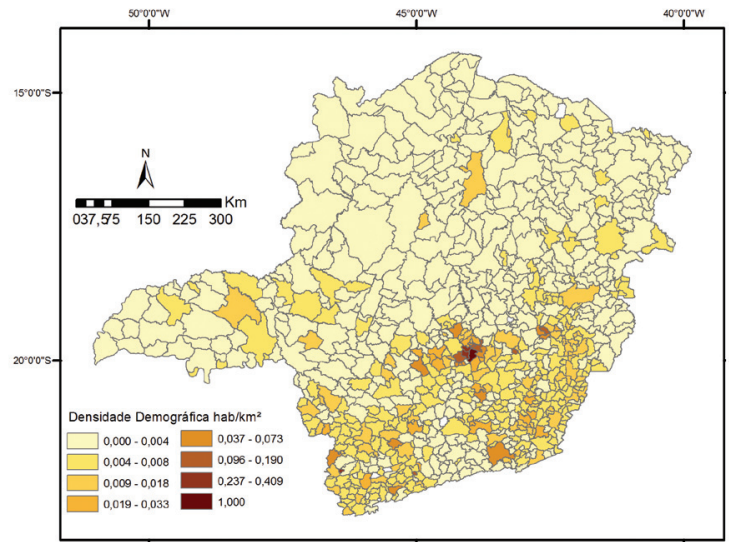

Fig. 3 - Densidade demográfica de Minas Gerais (Fonte: Silva, 2017)

Fig. 3 - Demographic density of Minas Gerais (Source: Silva, 2017).

QUADRo I - Informações sobre as universidades e número de e-mails válidos para a pesquisa (Fonte: Modificado de Silva, 2017).

TABLE I - Information on universities and number of valid e-mails for the survey (Source: Modified from Silva, 2017).

\begin{tabular}{|c|c|c|c|c|}
\hline Universidades & $\begin{array}{l}\text { Início do curso de } \\
\text { Geografia }\end{array}$ & $\begin{array}{l}\text { E-mails recebidos } \\
\text { em números }\end{array}$ & $\begin{array}{l}\text { E-mails válidos em } \\
\text { números }\end{array}$ & $\begin{array}{l}\text { Número de respostas obtidas a partir } \\
\text { dos e-mails enviados aos professores }\end{array}$ \\
\hline UFMG & 1946 & 90 & 27 & 10 \\
\hline UFJF & 1948 & 36 & 36 & 11 \\
\hline UNIMONTES & 1964 & 158 & 122 & 13 \\
\hline UFV & 2001 & 151 & 134 & 20 \\
\hline UFAL & 2007 & 69 & 57 & 10 \\
\hline UFTM & 2009 & 53 & 53 & 06 \\
\hline UFSJ & 2009 & 77 & 77 & 18 \\
\hline UFOP & 2010 & 01 & 01 & 01 \\
\hline UFU & 1971 & 0 & 0 & 0 \\
\hline UFVJM & 2009 & 0 & 0 & 0 \\
\hline \multicolumn{4}{|c|}{ Total de professores participantes até fevereiro de 2017.} & 89 \\
\hline
\end{tabular}


diversos gráficos e mapas elaborados com o recurso do $\operatorname{ArcGis} 10^{\circledR}$. As respostas obtidas com as questões abertas foram analisadas e organizadas em categorias, com base na técnica/método da Análise do Conteúdo (Bardin, 2002). Esta compreende um conjunto de técnicas de pesquisa cujo objetivo é a busca do sentido ou dos sentidos de um documento estudado. Bardin "configura a análise de conteúdo como um conjunto de técnicas de análise das comunicações, que utiliza procedimentos sistemáticos e objetivos de descrição do conteúdo das mensagens" (Campos, 2001, p.613). Segundo este autor, "um dado sobre conteúdo de uma comunicação é sem valor até que seja vinculado a outro e esse vínculo é representado por alguma forma de teoria" (Campos, 2001, p.613), passando pelas inferências. Nessa perspectiva, as inferências são embasadas em pressupostos teóricos e em situações concretas dos produtores do conteúdo, em contexto histórico e social.

$\mathrm{Na}$ pesquisa, as respostas dos professores foram analisadas individualmente e no conjunto de respostas apresentadas pelo próprio professor em cada questão, por meio de cruzamento, com o objetivo de aferir ideias e informações apresentadas nas questões fechadas e abertas. Além da análise individual de cada resposta, foram analisadas as respostas em conjunto, a fim de se identificar grupo de ideias e conhecimentos entre os professores participantes.

\section{Referencial teórico-conceitual da pesquisa}

Devido à natureza da pesquisa, foi importante eleger autores e leituras de referência que tratam do tema Riscos, como Almeida (2011a, 2011b), Faugéres (1995), Hewitt (2014), Marandola Júnior e Hogan (2004), Morandola Júnior e Silva (2015), Hogan e Marandola Júnior (2007), Lourenço (2006), Rebelo (2001, 2010), Smith (2001), Selby, D.; Kagawa, F (2012) e Veyret (2007) entre outros. E para discutir a noção de saberes docentes, considerou-se a contribuição de Maurice Tardif (2006).

Noção de Risco, risco natural e risco ambiental adotados na pesquisa

$\mathrm{Na}$ literatura são verificados estudos que consideram o risco concebido como onipresente, como constructo eminentemente social, ou seja, uma percepção humana (Veyret, 2007; Almeida, 2011a). Nessa vertente de pensamento Risco "é a percepção de um indivíduo ou grupo de indivíduos da probabilidade de ocorrência de um evento potencialmente perigoso e causador de danos, cujas consequências são uma função da vulnerabilidade intrínseca desse indivíduo ou grupo" (Almeida, 2011b, p.87). Na outra vertente, Risco está diretamente associada à função da combinação de dois aspectos, perigo e vulnerabilidade. Nessa perspectiva Risco corresponde à função resultante da relação entre perigo e vulnerabilidade, que pode ser entendido a partir da expressão: $f(R)=P \times V$; onde “[...] P é o próprio evento perigoso (perigo) ou a sua potencialidade de ocorrência, e $V$ é a vulnerabilidade intrínseca de um indivíduo ou grupo de indivíduos" (Almeida, 2011b, p.88). De acordo com Faugères (1990: 53), citado por Lourenço (2015: 8-9), o "risco" corresponde à "um sistema complexo de processos cuja modificação de funcionamento é suscetivel de acarretar prejuízos diretos ou indiretos (perda de recursos) a uma dada população". Nessa perspectiva, a noção corresponde a uma ocorrência potencialmente negativa, que poderá vir ou não a se manifestar (Lourenço, 2015).

A partir dessas vertentes de abordagem é possível encontrar estudos com ênfase nos processos perigosos e sua relação com a vulnerabilidade social, podendo essa está associada às condições socioeconômica, a ausência ou más condições de infraestrutura, à posição e localização geográfica das pessoas e grupos (Souza, 2016). E estudos com ênfase na perspetiva filosófica e epistêmica do termo risco. Para a pesquisa em andamento, ambas abordagens são importantes e não podem ser excludentes.

Risco ambiental é uma categoria considerada complexa em sua definição. Para Veyret e Richemond (2007, p.63), são entendidos como aqueles que "resultam da associação entre os riscos naturais e os riscos decorrentes de processos naturais agravados pela atividade humana e pela ocupação do território", sendo, então, uma noção que permite associar fatores do âmbito natural e social. Para Carpi (2001) e outros autores, o risco ambiental compreende todos os demais riscos e, portanto, constitui um termo sintético. Para Souza e Zanella (2009, p. 27), "[...] a expressão risco natural, apesar de sua forte vinculação com os fenômenos extremos da natureza, deve ser compreendida sob um ponto de vista mais amplo, que remete à noção de risco ambiental. Nesse sentido, esses riscos passam a ser tratados também como fenômeno social, já que atingem populações socialmente vulneráveis, como as que normalmente se instalam em áreas urbanas sujeitas a inundações e a escorregamentos".

Em Rebelo (2001) e Lourenço (2006), em suas classificações de riscos, o termo "risco ambiental" não é utilizado, mas riscos natural, antrópico e misto. Segundo Lourenço (2006, p. 109) riscos mistos são aqueles em que o "fenômeno que provoca o prejuízo apresenta causas combinadas, isto é, concorrem condições naturais $e$ ações antrópicas". Como exemplo Lourenço (2006) cita a redução da espessura da camada de ozônio, o agravamento do efeito estufa, as chuvas ácidas, a erosão acentuada pelo ser humano, o deslizamento acentuado pela ocupação humana, a desertificação 
por ação antrópica e o incêndio florestal provocado ou acentuado pelo homem, entre outros. Já os riscos naturais são aqueles que têm origem na natureza e possuem as seguintes subdivisões: geofísicos, climáticos, hidrológicos, geomorfológicos, hidro geomorfológicos e biológicos. Os riscos antrópicos são aqueles produzidos pela ação humana e são divididos em tecnológicos, sociais e biofísicos (Lourenço, 2006).

$\mathrm{Na}$ pesquisa adotou-se a concepção que distingue risco natural de risco ambiental, com base no princípio da gênese do processo perigoso. Nessa abordagem a gênese do processo pode ser eminentemente natural ou aquele natural agravado pela intervenção antrópica. Para efeito de se pensar os fenômenos naturais e seus processos e a intervenção antrópica, considera-se mais didático, no ensino de geografia, considera-los como distintos.

É fundamental pensar e discutir os riscos não como circunscritos a uma dimensão da realidade, mas que exprimem a complexidade da sociedade contemporânea em seus diferentes embates e natureza, conforme bem descreve Hogan e Marandola (2007). Nessa perspectiva, a ideia dos autores leva a pensar que na sala de aula o ensino do tema Riscos não pode se limitar à identificação, classificação, descrição e localização de áreas e de processos perigosos, mas estender essas ações e reflexões à dimensão política, econômica e social da realidade da população em questão, no contexto da totalidade espacial considerada.

\section{Saberes e práticas docentes}

A discussão sobre saberes está presente nos trabalhos e pesquisas de Pimenta (1996), Savianni (1996), Gauthier (1998), Tardif (2006) entre outros pesquisadores do campo da Educação. Apesar disso, para este texto consideraram-se as discussões realizadas por Tardif (2006), referentes ao entendimento da noção de saberes docentes disciplinar, saber curricular e saber da experiência considerados na condução da pesquisa e durante a análise das práticas dos professores.

O saber docente pode ser definido como "[... ] saber plural, formado pelo amálgama, mais ou menos coerente, de saberes oriundos da formação profissional e de saberes disciplinares, curriculares e experienciais" (Tardif, 2006, p. 36). No interior dessa concepção, os saberes disciplinares "[...] são saberes que correspondem aos diversos campos do conhecimento, aos saberes de que dispõe a nossa sociedade, tais como se encontram hoje integradas nas universidades, sob a forma de disciplinas, no interior de faculdades e de cursos distintos" (Tardif, 2006, p. 38).

Os saberes curriculares "correspondem aos discursos, objetivos, conteúdos e métodos a partir dos quais a instituição escolar categoriza e apresenta os saberes sociais por ela definidos e selecionados como modelos da cultura erudita e de formação para a cultura erudita" (Tardif, 2006, p. 38). E os saberes experienciais, na visão de Tardif (2006, p. 48), são o "conjunto de saberes atualizados, adquiridos e necessários no âmbito da prática da profissão docente e que não provêm das instituições de formação nem dos currículos". Eles, segundo o autor (2006, p. 49), constituem a cultura docente em ação.

Conforme discute Tardif (2006, p. 49), no exercício cotidiano do professor, na sala de aula e fora dela, aparecem condicionantes "relacionados a situações concretas que não são passíveis de definições acabadas e que exigem improvisação e habilidade pessoal, bem como a capacidade de enfrentar situações mais ou menos transitórias e variáveis". Essa situação contribui para que o docente desenvolva "habitus - isto é, certas disposições adquiridas na e pela prática real- que the permitirão justamente enfrentar os condicionantes $e$ imponderáveis da profissão".

Nessa concepção, o cotidiano e a experiência, como modos que transforma o professor e o seu fazer frente aos condicionantes da profissão e da sala de aula, transformam também a prática do docente à medida que ocorre o distanciamento temporal entre o conhecimento adquirido na academia e o construído no âmbito escolar. Para Huberman (1995), professores que tem entre um a cinco anos de profissão, embora estejam mais próximos dos conhecimentos acadêmicos que os formaram, apresentam dificuldades com a realidade profissional podendo dela desistir. Segundo o autor, a iniciação na docência é um período de aprendizagens intensas, que pode traumatizar e despertar no professor a necessidade de sobreviver aos desafios da profissão.

Na pesquisa, a opção por se trabalhar com professores recém formados, egressos entre 2011 e 2015, adveio do fato de se considerar que o conhecimento e práticas apresentadas no cotidiano e na vida profissional resultam em grande parte dos saberes disciplinares e curriculares, ainda sob influência da formação acadêmica e dos saberes das experiências, ainda que em pouco tempo de atuação profissional. Dessa forma, foi possível associar grande parte das respostas apresentadas pelos professores, no quesito conceitos, conteúdos e práticas referentes a temática risco e risco ambiental, à formação inicial recebida durante a graduação e a fatos que ocorreram no Brasil a partir de 2010.

No período de 2010 e 2014 ocorreram decisões governamentais referentes à questão do Risco e desastres naturais, como a Lei $12.608 / 12$, que prevê a inclusão dos princípios da proteção e defesa civil e educação ambiental nas unidades de educação (BRASIL, 2012). E, ainda, nesse período ocorreram congressos brasileiro de desastres naturais, em 2012 e 2014, entre outros eventos regionais. Portanto, 
era esperado que esses fatos tenham sido abordados na formação inicial dos professores participantes da pesquisa ou mesmo nas suas práticas.

\section{Resultados e discussão}

Durante a pesquisa dezenas e centenas de informações foram levantadas por meio do questionário online, as quais foram organizadas, classificadas segundo diversos assuntos. Neste texto são apresentados e discutidos os resultados específicos sobre o conhecimento dos professores quanto à noção de risco e risco ambiental, sem a intenção de negligenciar ou esgotar as outras possibilidades de discussão dos dados e informações levantados, os quais serão tratados em outra oportunidade.

\section{Conhecimento e contribuição de professores de geografia para o tema risco ambiental}

As respostas obtidas em diversas questões foram analisadas individualmente e depois relacionadas umas às outras, com interesse em averiguar se a resposta apresentada em uma questão fechada era confirmada ou não em uma segunda e terceira respostas advindas de questões abertas que permitiam retomar questões anteriores e serem aferidas via cruzamento das mesmas, conforme exemplificado no QUADRo II.

Por meio desse procedimento de análise, constatou-se, em questão fechada, que $81,8 \%$ do professores afirmaram que risco significa "probabilidade, possibilidade de ocorrência de um determinado evento e suas consequências para a população e ou indivíduo" e outros, 13,6\% indicaram a ideia de risco como "qualquer desastre natural ou antrópico, ou seja, aquele ocorrido por fenômenos naturais ou sociais", enquanto 2,4\% afirmaram que risco é "mudança natural e ou artificial de causa humana no ambiente"; $1,1 \%$ entenderam risco como "qualquer alteração no meio ambiente provocado pela ação humana" e 1,1\% marcaram não ser nenhuma dessas definições. Nessa questão, a grande maioria indicou a resposta esperada como sendo a mais satisfatória.

Quanto a definição do termo "risco ambiental", a opção mais apropriada, solicitada na questão número 17 do questionário, foi indicada por 77,3\%. Para esses, risco ambiental é a associação entre riscos naturais e riscos decorrentes de processos naturais agravados pela atividade humana e pela ocupação do território. Essa resposta está fundamentada nas discussões de Veyret (2007) e Almeida (2011a; 2012) que consideram o risco ambiental como um tipo de risco diferente do natural e que ocorre devido à intervenção humana sobre os processos naturais. Para 9,0\% dos professores, risco ambiental é definido como degradação dos elementos da natureza devido as atividades e a ação humana; para $3,4 \%$ significa qualquer alteração no meio ambiente provocada pela ação humana; para 2,3\% risco ambiental pode ser mudança natural ocasionada pelos fenômenos da natureza com impacto no ambiente e para $8 \%$ não consideraram nenhuma das alternativas (Silva, 2017).

Apesar de haver um índice alto para a definição de risco e risco ambiental, apresentadas em questões fechadas, considerados mais adequados de acordo com a concepção adotada na pesquisa, quando as respostas de cada pessoa foi analisada no conjunto de suas outras respostas, foi possível verificar que muitos, apesar de indicarem satisfatoriamente a definição de risco e de risco ambiental, apresentaram respostas pouco

QuAdro II - Modelo de cruzamento de pergunta e reposta por pessoa (Fonte: Modificado de Silva, 2017).

TABLE II - Question and answer cross-over model per person (Source: Modified from Silva, 2017).

\begin{tabular}{|c|c|c|c|c|c|}
\hline Participante & $\begin{array}{l}\text { Acertou o } \\
\text { conceito } \\
\text { de risco }\end{array}$ & $\begin{array}{l}\text { Acertou o } \\
\text { conceito de } \\
\text { risco ambiental }\end{array}$ & $\begin{array}{l}\text { Associou corretamente } \\
\text { o conceito às imagens } \\
\text { de risco ambiental }\end{array}$ & $\begin{array}{l}\text { Citou exemplo } \\
\text { incorreto de } \\
\text { risco ambiental }\end{array}$ & $\begin{array}{c}\text { Em suas respostas abertas e fechadas } \\
\text { foi evidenciada confusão } \\
\text { com degradação }\end{array}$ \\
\hline Participante 1 & Sim & Sim & Sim & Sim & $\begin{array}{l}\text { SIM, questão } 22 \text { “Depósito inadequado } \\
\text { de lixo urbano, esgoto lançado no có- } \\
\text { rrego que corta o centro da cidade”. }\end{array}$ \\
\hline Participante 24 & Sim & Sim & Sim & Sim & $\begin{array}{l}\text { SIM, questão } 22 \text { “Mineração. Monocul- } \\
\text { tura de eucalipto". }\end{array}$ \\
\hline Participante 30 & Sim & Sim & Sim & Sim & $\begin{array}{l}\text { SIM, questão 29- “Estes temas devem } \\
\text { ser muito bem trabalhados e retra- } \\
\text { balhados em sala, para que os alunos } \\
\text { criem uma maior consciência diante do } \\
\text { impacto ambiental que causamos no } \\
\text { meio ambiente e que precisamos mi- } \\
\text { tigar as potencialidades causadoras de } \\
\text { dano ambiental". }\end{array}$ \\
\hline
\end{tabular}


satisfatórias quanto à exemplificação e definição dos referidos termos. Um exemplo dessa situação referese à questão na qual os professores foram solicitados a relacionarem diversas imagens (fig. 4 e fig. 5) como representações de risco natural e risco ambiental. 0 índice geral de acerto foi menor do que nas duas questões anteriores, referentes à concepção de risco e risco ambiental.

Do total de professores, 53,4\% fizeram a relação esperada entre a ideia de risco ambiental e risco natural nas representações imagéticas, concebendo a ideia desses riscos segundo a discussão de Veyret (2007) e de Lourenço (2006). Outros 40,9\% consideraram todas as imagens como representando risco ambiental. Pode dizer que essa resposta se fundamentada na proposta de alguns geógrafos e geólogos que consideram o risco ambiental como a categoria maior dos riscos.

A pesar de se verificar porcentagem elevada nas respostas consideradas satisfatórias para a definição de riscose riscos ambientais, as respostas, de cada professor, analisadas no conjunto de suas outras respostas, principalmente nas

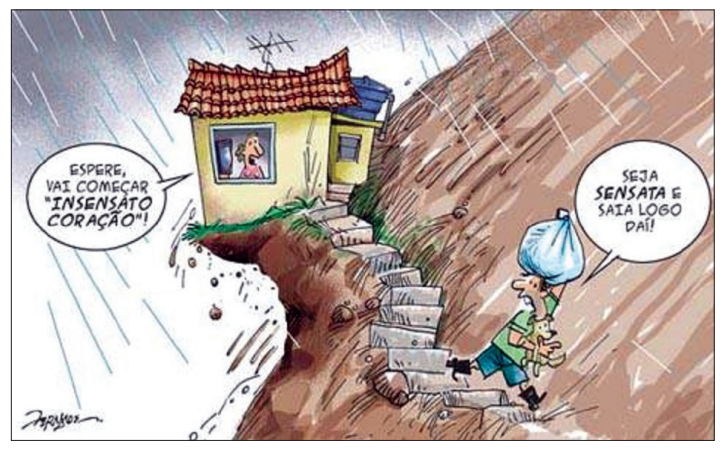

Fig. 4 - Ocupação em área de encosta (Fonte: http://www.nachapaquente.com.br/2014/07/.

Fig. 4 - Occupancy in hillside area (Source: http://www.nachapaquente.com.br/2014/07/).

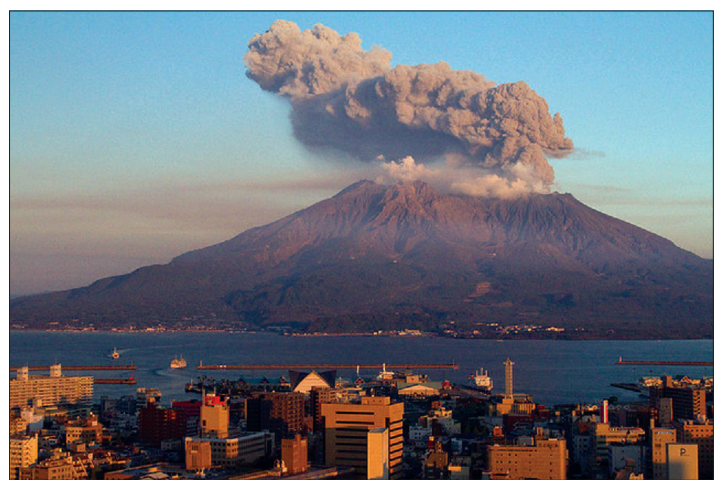

Fig. 5 - Vulcão em Sacurajima/Japão, 2013

(Fonte: http: / /issoeofim.blogspot.com.br/2013/07/no-japao-ovulcao-sakurajima-e-abalado.html).

Fig. 5 - Volcano in Sacurajima, Japan, 2013

(Source: http://issoeofim.blogspot.com.br/2013/07/no-japaoo-vulcao-sakurajima-e-abalado.html). questões abertas, mostraram que muito dos professores, apesar de indicarem satisfatoriamente a definição de risco e de risco ambiental, apresentaram respostas pouco satisfatórias quanto à exemplificação e definição dos referidos termos.

Entre os 37 participantes $(40,9 \%)$ que consideraram todas as imagens representando risco ambiental, quase a metade (18) deles considerou que risco ambiental corresponde à degradação, considerando-os sinônimos. Ainda em suas respostas abertas notou-se que a ênfase foi dada para a ideia de meio ambiente e ou questões referentes à problemas ambientais. Entre as respostas verificou-se o uso das expressões "poluição das águas, poluição do ar, desmatamento, queimadas, lixo, depósito de entulhos, entre outros, para dizer dos efeitos negativos que a sociedade causa sobre os elementos físico-naturais, em função de suas práticas sociais e econômicas no espaço" (Silva, 2017).

A confusão entre o significado risco ambiental com degradação e impacto ambiental ficou mais evidente ao analisar os exemplos apresentados pelos professores referentes ao tipo de risco ambiental presente no município em que trabalham. Entre os exemplos citados, tem-se "contaminação do solo por venenos e água especificamente nas zonas rurais, por uso não potável" (Participante 23); "Poluição sonora e atmosférica" (Participante 35) e "assoreamento de córregos $e$ despejos de esgoto" (Participante 68).

Este mesmo fato foi observado por Ferreira, Taroco e Souza ( 2016) ao pesquisarem a concepção de professores e alunos do ensino fundamental e médio de duas escolas públicas em uma cidade no interior de minas, durante pesquisa de iniciação científica.

Embora o assunto riscos ambientais possa ser discutido no âmbito da questão ambiental mais geral, ele diferenciase dos demais temas ambientais por sua especificidade. Esta refere-se a percepção da relação vulnerabilidade, perigo e evento danoso que traz perdas para as pessoa ou grupos, colocando as pessoas e a população como ponto central da discussão e não os elementos físico-naturais, que são tomados como recursos.

Acredita-se que a associação realizada pelos professores entre risco ambiental e problemas ambientais, como degradação está diretamente ligada à presença da questão ambiental nos estudos e pesquisas de geografia intensificados a partir de 1990 e contemplados em livros textos, em eventos científicos e mais intensificados nas pesquisas brasileiras a partir da referida década.

A questão ambiental ganhou ênfase nas últimas décadas, principalmente depois das Conferências Mundiais para o Desenvolvimento Sustentável (ECO-92 e Rio + 20) e outros encontros e fóruns mundiais, regionais e locais. No Brasil, está presente também na Constituição e em 
vários documentos nacionais sobre educação, como nos Parâmetros Curriculares Nacionais (PCN'S), no qual Meio Ambiente é considerado como tema transversal a ser trabalhado no ensino das diversas disciplinas escolares e, principalmente, naquelas envolvidas com meio ambiente (Geografia, Ciências e Biologia). A questão ambiental também está muito presente nos vários meios de comunicação (Silva, 2017).

Ao responderem sobre as unidades curriculares acadêmicas que mais contribuíram para a sua formação e conhecimento a respeito de riscos ambientais, as disciplinas relacionadas à geografia física foram as mais citadas, como geomorfologia (citada 39 vezes), climatologia (29), geologia (15) e hidrologia (14), seguida da geografia urbana (13) no âmbito da geografia humana e educação ambiental (4).

Para investigar o conjunto de respostas apresentadas pelos professores, elaborou-se um quadro síntese contendo cinco questões retiradas e adaptadas do questionário. 0 objetivo foi aferir o conhecimento dos professores sobre o tema risco ambiental. Para isso, durante as análises fizeram-se as seguintes questões: o professor abordou os conceitos de risco e risco ambiental satisfatoriamente? Citou exemplo satisfatório de risco ambiental? Apresentou confusão entre risco e degradação nas questões?

A partir da análise e organização de cada resposta, identificaram-se quatro grupos de conhecimentos, exemplificados no QUADRO III e descritos em seguida.

A partir da classificação das respostas em grupos é possível afirmar que entre os professores de Minas Gerais que participaram da pesquisa, apenas $25 \%$ demonstram conhecer bem o tema risco e risco ambiental. A maioria $66 \%$, conhece o assunto parcialmente e apresenta certa dúvida entre risco ambiental e degradação ambiental (30\%), enquanto outros (36\%) demonstram dúvidas também quanto ao termo risco. A porcentagem de professores que demonstraram conhecer muito pouco o assunto é baixa (9\%), se comparada com os demais grupos.

QUADRo III - Representação das respostas satisfatórias por grupo: exemplos (Fonte: Data da pesquisa 2016/2017. Modificado de Silva, 2017).

TABLE III - Representation of satisfactory responses by group: examples (Source: Research Date 2016/2017. Modified from Silva, 2017).

\begin{tabular}{|c|c|c|c|c|}
\hline Participante & $\begin{array}{l}\text { Conceito de } \\
\text { risco - Satisfatório }\end{array}$ & $\begin{array}{l}\text { Conceito de risco } \\
\text { ambiental - Satisfatório }\end{array}$ & $\begin{array}{l}\text { Citou exemplo de risco } \\
\text { ambiental - satisfatório }\end{array}$ & $\begin{array}{l}\text { Em todas as respostas, demonstrou cla- } \\
\text { reza entre degradação e risco ambiental }\end{array}$ \\
\hline Participante 42 & Sim & Sim & Sim & Sim \\
\hline Participante 49 & Sim & Sim & Sim & Sim \\
\hline Participante 62 & Sim & Sim & Sim & Sim \\
\hline Participante 32 & Sim & Sim & Sim & Não \\
\hline Participante 89 & Sim & Sim & Sim & Não \\
\hline Participante 87 & Sim & Sim & Não & Não \\
\hline Participante 71 & Não & Sim & Não & Não \\
\hline Participante 25 & Não & Sim & Não & Não \\
\hline Participante 54 & Não & Não & Sim & Não \\
\hline Participante 29 & Não & Não & Não & Não \\
\hline Participante 11 & Não & Não & Não & Não \\
\hline Participante 18 & Não & Não & Não & Não \\
\hline
\end{tabular}

Grupo 1 - Participantes que responderam satisfatoriamente o conceito de risco/risco ambiental em todas as questões, fechadas e abertas (22 pessoas), demonstrando conhecimento muito satisfatório quanto ao tema (25\% dos professores)

Grupo 2 - Participantes que apresentam conhecimento satisfatório quanto a risco e risco ambiental em questões fechadas, mas nas questões abertas relacionaram, em alguns momentos, os termos à ideia de degradação (27 pessoas), demostrando certa confusão entre o emprego do tema risco ambiental e degradação ambiental em algumas situações. (30\%)

Grupo 3 - Participantes que apresentam conhecimento pouco satisfatório do conceito de risco/risco ambiental nas questões fechadas e abertas (32 pessoas). Este grupo apresenta menos segurança e clareza quanto ao tema se comparado com o grupo 2. Apresenta mais respostas negativas do que o grupo2. (36\%)

Grupo 4 - Todos participantes responderam de maneira muito insatisfatória os conceitos de risco e risco ambiental, tanto nas questões fechadas quanto nas abertas (8 pessoas). Neste grupo, o conhecimento dos professores sobre o tema é muito insatisfatório, as respostas são predominantemente negativas ( $9 \%$ ). 
Acredita-se que essa classificação possa ser estendida a outras regiões mineiras, o que mostra a existência de um grupo grande de professores que conhecem o assunto, mas apresentam dificuldades com algumas nomenclaturas e definições, como as verificadas no grupo 2 e 3 , descritos no texto, que somados totalizam $66 \%$ no caso da pesquisa.

Esse resultado leva a pensar na necessidade de se trabalhar melhor a temática risco e risco ambiental na formação inicial dos professores de geografia em Minas Gerais, bem como a necessidade de se inserir tal assunto como conteúdo em disciplina acadêmica específica, diferente das que trabalham com Meio Ambiente (citado 31 vezes pelos professores), Avaliação e impacto ambiental (11) ou geomorfologia ambiental (4).

Para a formação dos graduandos da licenciatura, que irão trabalhar com o ensino de geografia, o ideal é que possam vivenciar, ainda na graduação, uma unidade curricular que possibilite a interação entre os conteúdos do núcleo específico da Geografia e os do campo da Pedagogia e das Práticas de ensino, superando assim o distanciamento existente entre esses dois núcleos que compõem a estrutura curricular dos cursos de geografia brasileiro, modalidade licenciatura. Ainda nessa perspectiva de integração, cabe desenvolver as temáticas ligadas à riscos e riscos ambientais considerando, por exemplo, a relação cidade e riscos ambientais, campo e riscos ambientais entre outras propostas, como já começa a aparecer em uma ou outra universidade, de maneira pontual. Em uma das universidades citadas na pesquisa, foi criado o Grupo de Estudos e Pesquisas em Geografia, Educação e Riscos (GEPEGER), reconhecido pelo CNPq desde 2014, com trabalhos no âmbito do Ensino, Pesquisa e Extensão.

Risco ambiental nas práticas docente de professores de Minas Gerais

Retomando os resultados da pesquisa, ao propor aos professores que discorressem sobre sua prática em sala de aula com o tema risco e risco ambiental foi possível verificar um pequeno número de participantes (12,3\%) que efetivamente descreveram práticas nas quais 0 referido tema esteve presente. Nas práticas desses professores, os recursos e procedimentos pedagógicos adotados são projetos, debates, registro fotográfico e confecção de mapas, conforme citado por eles e exemplificado a seguir:

- Desenvolvi um projeto em uma escola sobre riscos ambientais, em que trabalhei com os deslizamentos de terra ocorridos na cidade após um período de intensa precipitação. Os estudantes tiraram fotos dos locais para o debate das consequências destes eventos e foi confeccionado um mapa, no Google
Earth, para localização dos pontos de ocorrência. Os estudantes também confeccionaram cartazes para um mural para apresentação de todo o projeto para os demais estudantes e equipe da escola (Participante 43, grifo nosso).

- Indiretamente, quando eu estava trabalhando o conceito de lugar. Surgiu, por parte do aluno, a questão do rompimento da barragem da mineradora Samarco. A partir de então, a explicação baseouse na relação de valor e uso das empresas e o valor afetivo do espaço, buscando compreender os sentimentos dos moradores de Bento Rodrigues (Participante 47, grifo nosso).

- Eu leciono Geografia para os alunos do $3^{\circ}$ e $4^{\circ}$ ano do Ensino Fundamental e a compreensão do espaço por esses alunos ainda é um pouco complicada. Por isso, busco trazer exemplos práticos, da vivência cotidiana para ilustrar diferentes conteúdos. 0 concreto, o visível é mais palpável didaticamente. Então, foi abordado em sala os riscos ambientais relacionados a diferentes paisagens e elementos. Foi abordado de maneira direta os riscos de contaminação (ar, água, solo) e as consequências da ação humana no ambiente natural e para a própria população. Alguns desses conteúdos são propostos nos documentos oficiais, com a relação sociedade $e$ natureza (Participante 61, grifo nosso)

- Quando tivemos o desastre ambiental de Marianal MG, trabalhei com os alunos quais possíveis riscos das usinas hidrelétricas, ou outros empreendimentos poderiam trazer consequências para o município de Uberlândia (Participante 26, grifo nosso).

- Uso de imagens de voçoroca pelo computador, os alunos aprendem melhor com imagens. Exemplo de uma tempestade ocorrida na cidade, mostrando os estragos através da experiência de cada um em seu bairro (Participante 6, grifo nosso).

Nota-se que esses professores apesar de priorizarem a citação do conteúdo e do procedimento didático adotado, é possível perceber também a intenção em trazer conteúdos que remetem à questão da importância do estudo do espaço, dos processos naturais e sociais e a relação com a temática risco ambiental. Verificaram-se, ainda, entre os professores que descreveram sua prática, elementos que remetem ao conhecimento construídos durante a formação em Geografia, por exemplo os conceitos lugar e paisagem - citados, por exemplo, pelos participantes 43 e 47, conhecimentos vindos das experiências nas cidades nas quais moram ou lecionam (participantes 43, 47 e 61); conhecimentos com base no currículo oficial e ou da escola na qual leciona (participante 61). Esses participantes ao descreverem sua prática usam de uma pluralidade de saberes (Tardif, 
2006), ou seja, saberes vindos da formação acadêmica e da disciplina de Geografia, saberes da experiência e saberes curriculares.

Em suas descrições sobre a prática com o tema é possível perceber procedimentos adotados (debate, confecção de mapas e cartazes e explicação), o uso de conceitos chave (paisagem e lugar) e o interesse em buscar a visão crítica entre os alunos. Esses aspectos observados nas "falas" dos professores são discutidos por Antoni Zabala (2010) como conteúdos considerados de natureza procedimental, conceitual e atitudinal. Os conteúdos conceituais referem-se à construção ativa de capacidades intelectuais para operar símbolos, imagens, ideias, conceitos e representações que permitam organizar as realidades. Os conteúdos procedimentais referem-se ao fazer com que os alunos construam instrumentos para analisar, por si mesmos, os resultados que obtém e os processos que colocam em ação para atingir as metas que se propõem. Já os conteúdos atitudinais referemse à formação de atitudes e valores em relação à informação recebida, visando a intervenção do aluno em sua realidade (Zabala, 2010).

É interessante destacar que apenas 12,3\% do professores discorreram sobre suas práticas efetivas com a temática risco ambiental. Apesar desta porcentagem, 43,2\% do total de participantes marcaram a questão "consideram conhecer bem o assunto e realizam práticas que permitem trabalhá-los nas aulas de Geografia”. Esse total de 43,2\% refere-se, em grande parte, aos grupos 1 e 2 que demonstraram conhecimento satisfatório quanto ao tema risco e riscos ambientais com dúvidas eventuais, apesar de apenas 12,3\% realmente explicitarem suas práticas. Alguns informaram não estar lecionando no momento. Outros professores, 28,4\%, declaram conhecer bem o assunto, mas trabalham pouco com ele nas aulas de Geografia; 25\% indicaram que gostaria de conhecer melhor o assunto para trabalhá-lo nas aulas de Geografia e 3,4\% conhecem pouco o assunto e, portanto, não trabalham com ele na aula de Geografia.

A somatória da porcentagem dos professores que indicaram querer conhecer melhor o assunto ou conhecem pouco e trabalham pouco ou não trabalham o tema somam $28,4 \%$, assim como os que conhecem bem mas não trabalham. Dessa forma, tem-se um total de $56,8 \%$ de professores que indicaram não trabalhar o tema independente do conhecimento que se tem sobre risco e risco ambiental.

Apesar dessa diferença de valores entre o verificado na questão aberta sobre a prática com o conteúdo (12,3\%) e a indicação, em questão fechada, sobre o trabalhar em sala com o tema $(43,2 \%)$, o que se verifica no geral é a baixa presença do assunto risco ambiental entre os conteúdos e a prática de ensino dos professores mineiros, participantes da pesquisa. Esse fato pode ser confrontado com as respostas apresentadas à questão referente à quando o assunto é trabalhado em sala de aula, conforme representado na fig. 6.

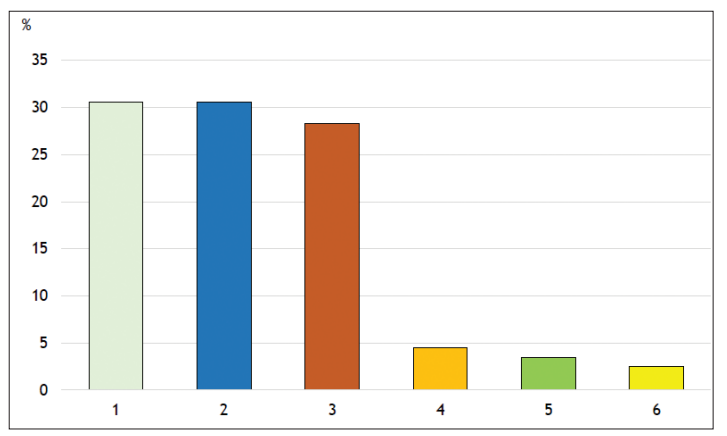

Fig. 6 - Momento quando o assunto é trabalhado nas aulas de Geografia (Fonte: Dados da pesquisa, 2016/2017).

1 - Não se aplica; 2- Quando aparece no livro didático;

3- Quando ocorre algum evento próximo à escola; 4 - Quando aparece na mídia; 5 - Quando perguntado pelo aluno; 6 - Raramente.

Fig. 6 - Time when the subject is dealt with in geography classes (Source: Research data, 2016/2017).

1 - Does not apply; 2- When it appears in the textbook; 3- When there is an event near the school; 4 - When it appears in the media; 5 - When asked by the student; 6 - Rarely.

A soma dos que indicaram trabalhar o assunto quando abordado no livro didático $(30,6 \%)$ e quando ocorre algum episódio nas proximidades da escola $(28,3 \%)$ ou espaço de vivência do aluno chega à $58,9 \%$. Mas, sabe-se que essa temática nos livros didáticos é ainda incipiente e não está presente em muitos desses livros. Diante disso, considera-se que o tema é pouco abordado na sala de aula pelos professores.Acredita-se que esse fato se repita em várias outros municípios e nas mesorregiões do estado mineiro, ainda que não contemplados na pesquisa. Isso se deve ao fato de o livro didático ser o recurso didático presente em quase a totalidade das redes de ensino em Minas Gerais. Para aferir a situação real do tema riscos naturais e riscos ambientais nos livros do ensino médio, mais adotados no Brasil, está em andamento outra pesquisa, desenvolvida por membros do Grupo de Estudos e Pesquisa em Geografia, Educação e Riscos, com defesa prevista para 2018.

Os professores da pesquisa que realizam práticas de ensino com o tema, residem e ou trabalham nos municípios de Viçosa (4 participantes), Belo Horizonte (3), São João del-Rei (2), Juiz de Fora e Prados (1). Esses municípios estão localizados nas Mesorregiões Zona da Mata, Metropolitana de Belo Horizonte e Campos das Vertentes, situadas na porção Centro-Sul e Sudeste de Minas Gerais (fig.1).

Os professores, residentes nas mesorregiões situadas na porção norte e nordeste do estado, ao citarem algum exemplo de assunto tratado durante as aulas de geografia e que podem ser associados à questão riscos ambientais 
citaram casos que ocorreram em outras localidades do sudeste brasileiro, como os deslizamentos nas regiões serranas do Rio de Janeiro, o desastre resultante do rompimento da barragem da Samarco em Marina e alguns casos de inundação nos grandes centros urbanos. Esse fato mostra que apesar de viverem em região onde os problemas referem-se à questão da escassez de água devido ao longo período de estiagem e seca (fig. 7 e fig. 8), os exemplos indicados pelos professores são os das regiões chuvosas no sudeste brasileiro e centro e sul de Minas Gerais.

De acordo com Prudente (2011), os municípios localizados nas mesorregiões Norte, Jequitinhonha e Vale do Mucuri apresentam risco alto, caso ocorra precipitação acima de $100 \mathrm{~mm}$ em um dia, devido às condições socioeconômica e à infraestrutura, combinadas com os índices da densidade demográfica, IDH (Índice de Desenvolvimento Humano) e índice de pobreza, entre outros parâmetros. Esse fato, apesar de se referir às consequências caso ocorram alterações climáticas na região, evidencia a situação de maior vulnerabilidade social da população dessas regiões se comparadas às demais de Minas Gerais.

Os mapas das fig.s 7 e 8 , elaborados a partir de pesquisa realizada junto ao Boletim de Ocorrência da Defesa Civil do estado de Minas Gerais durante 2015, 2016 e 2017 (Rufino et al., 2016), mostram a relação de municípios que decretaram estado de emergência ou de calamidade pública em 2015, devido ao longo período de estiagem e seca.

Associado à situação de seca e estiagem aparece o problema de incêndios, indicado por $90 \%$ dos professores residentes na porção norte mineira, como sendo

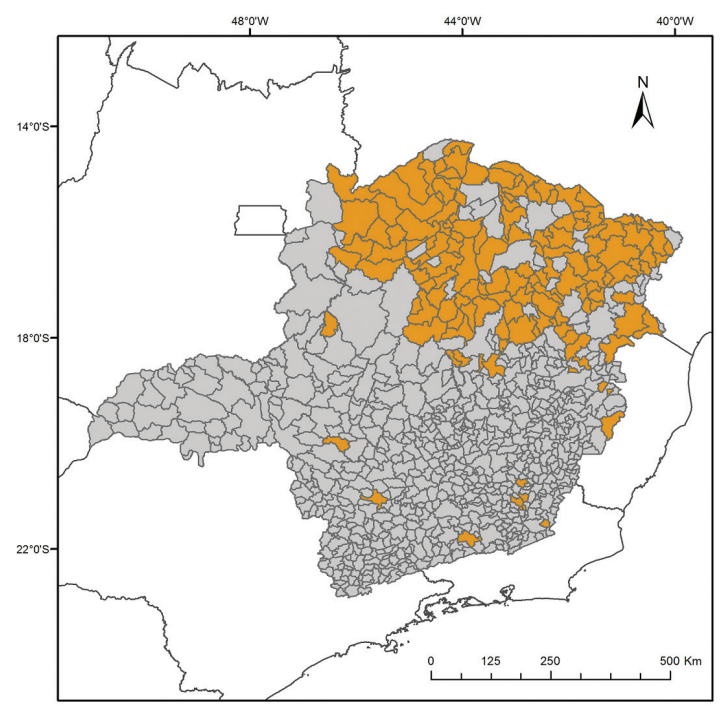

Fig. 7 - Ocorrência de estiagem em 2015, de acordo com Boletim da Defesa Civil de Minas Gerais (Fonte: Dados da pesquisa 2016).

Fig. 7 - Lack of rain in 2015, according to the Minas Gerais Civil Defense Bulletin

(Source: Research data 2016). frequentes no município onde residem ou trabalham. Apesar de reconhecerem os incêndios como um tipo de risco presente na região, os mesmos não são citados quando solicitados a falarem sobre prática em sala de aula referente ao tema riscos ambientais. Esse fato vem reforçar a importância de se trazer para a formação inicial de professores de geografia a abordagem das ciências cindínicas, com destaque para a análise dos tipos de riscos que ocorrem na região de residência dos professores.

\section{Conclusão}

Ao retomar as questões iniciais - "Os professores de Geografia conhecem o significado do termo Risco ambiental e reconhecem em sua região, ou cidade, áreas de risco ambiental?" e "Este assunto é trabalhado nas aulas de geografia?” - é possível dizer que os professores mineiros de modo geral conhecem o termo, mas o entendimento do mesmo com base nas discussões no contexto das ciências cindínicas ainda é restrito a poucos. O conhecimento dos professores está pautado nas discussões e visões sobre a temática ambiental. Dessa forma, ao conciliarem risco ambiental e questões ambientais conseguem indicar em suas regiões e cidades áreas de riscos. E, também, com base nessa perspectiva ambiental, alguns professores consideram trabalhar a temática risco ambiental em suas práticas na sala de aula. Porém, observou-se que tal prática acontece entre alguns professores e não entre a maioria.

Verifica-se um descompasso entre o que se tem no papel, nos estudos, na legislação e o que ocorre nas escolas públicas mineiras, no contexto dos conteúdos e

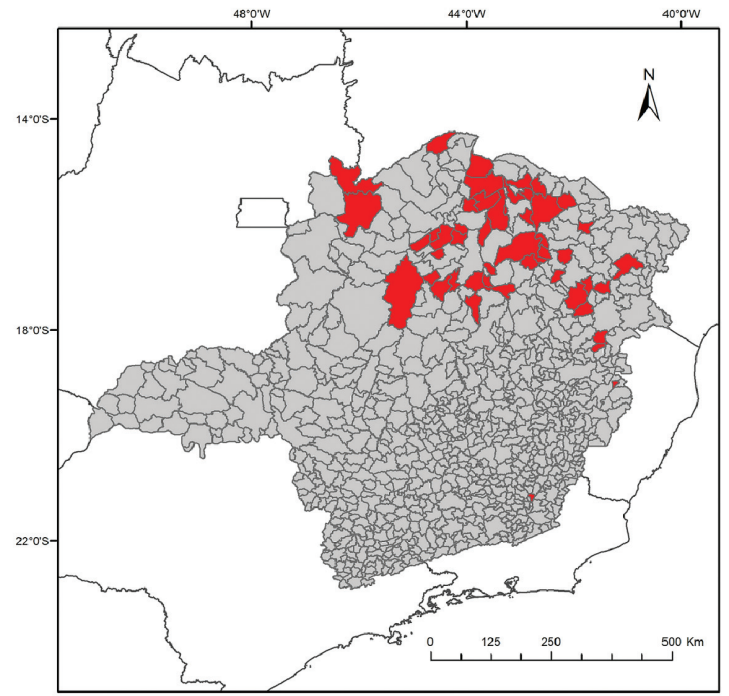

Fig. 8 - Ocorrência de seca em 2015, de acordo com Boletim da Defesa Civil de Minas Gerais

(Fonte: Dados da pesquisa 2016).

Fig. 8 - Drought in 2015, according to the Minas Gerais Civil Defense Bulletin

(Source: Search data 2016). 
discussões geográficas sobre risco ambiental na sala de aula e na prática dos professores, apesar de existirem informações referentes à riscos ambientais e naturais disponibilizados em sites públicos, em pesquisas e discussões em eventos científicos. Isso significa dizer que o tempo das pesquisas e discussões realizadas no âmbito acadêmico e das políticas públicas não corresponde ao tempo de efetivação dessas discussões no âmbito da escola. Portanto, verifica-se a necessidade de diálogos diretos e objetivos com os sujeitos escolares por meio de ações e eventos com e para professores e graduandos em licenciaturas.

A partir dos resultados alcançados com a pesquisa, tornou-se possível pensar e propor encontros, seminários, minicursos e formação continuada que considerassem a temática Educação para o risco ambiental, no contexto da proposta de Redução de Riscos de Desastres, para professores da rede pública e privada e graduandos em Geografia, em eventos e ações em escala local e regional, em algumas cidades do sul e sudeste mineiro.

A Geografia, por intermédio de seus profissionais professores, pode e deve contribuir com conhecimentos específicos e científicos referentes ao risco ambiental, ao abordar a questão da existência de perigo e processos de ordem natural e antrópico presentes na cidade e no campo, ao problematizar a organização e produção desses espaços considerando a relação de uso e ocupação da terra, do solo, do relevo, do espaço e a consequente geração de áreas e territórios de riscos ambientais.

O entendimento desses processos naturais e sociais, a interação entre eles, principalmente na escala geográfica local permite aos jovens, em processo de formação básica, conhecer e perceber os riscos ambientais eminentes em seu espaço de vivência. 0 entendimento e a percepção dos riscos pelos jovens os conduzem para medidas de atenção, alertas e cuidados, logo para possível prevenção e, consequentemente, a redução de riscos de desastres.

\section{Referências bibliográficas}

Allen, J. (2012). Guia prático de redução de riscos de desastres - uma experiência com jovens na Região Serrana do Rio de Janeiro. São Paulo: Fundação Abrinq pelos Direitos da Criança e do Adolescente.

Almeida, L. Q. (2011a). Por que as cidades são vulneráveis? Revista da Casa da Geografia de Sobral, Ceará, v. 13, p. 70-82. Disponível em: www.uvanet.br. Acesso em: 10 mar. 2015.

Almeida, L. Q. (2011b). Por uma ciência dos riscos $e$ vulnerabilidades na Geografia. Mercator, Fortaleza, v. 10, n. 23, p. 83-99. Disponível em: http://www. mercator.ufc.br. Acesso em: [08/02/2017].
Almeida, L. Q. (2012). Riscos ambientais e vulnerabilidades nas cidades brasileiras: Conceitos, metodologias $e$ aplicações. 1. ed. São Paulo: Cultura Acadêmica. Disponível em: http://www.culturaacademica.com.br. Acesso em: [10/02/2016].

Bardin, L. (2002) Análise de conteúdo. Lisboa: Edições 70, $229 \mathrm{p}$.

BRASIL (2012). Congresso Nacional. Lei $n^{\circ}$ 12.608, de 10 de abril de 2012. Política Nacional de Proteção e Defesa Civil. Classificação dos Desastres. Brasília, DF. Disponível em: www.planalto.gov.br. Acesso em: [08/02/2017].

BRASIL (1998). Parâmetros Curriculares Nacionais de Geografia. Secretaria de Educação Brasília: MEC/ SEF. Disponível em: http://portal.mec.gov.br/seb/ arquivos/pdf/geografia.pdf. Acesso em: [12/12/2017].

Campos, C. J. G. (2001). Método de análise de conteúdo: ferramenta para a análise de dados qualitativos no campo da saúde. Revista Brasileira de Enfermagem. Brasília (DF) set/out;57(5):611-4. Disponível em: http://www.scielo.br/pdf/reben/v57n5/a19v57n5.pdf. Acesso em [08/02/2017].

Carpi Jr., S. (2001). Processos erosivos, riscos ambientais e recursos hídricos na Bacia do Rio Mogi-Guaçu (Tese de Doutorado em Geociências e Meio Ambiente). Rio Claro: IGCE/UNESP, 188 p. Orientação: Prof. Archimedes Perez Filho. Disponível em: www.nepam.unicamp.br/ downloads/tese_final_salvador.pdf. Acesso [05/04/2016].

Cerri, L. E. S. e Amaral, C. P. (1998). Riscos Geológicos. In: Oliveira, A. M. S. e Brito, S. N. A. (eds.) 1998. Geologia de Engenharia. São Paulo, ABGE

CENTRO NACIONAL DE MONITORAMENTO E ALERTA DE DESASTRES NATURAIS (2016). Cemaden Educação. Disponível em: http://www.cemaden.gov.br/cemaden-educacao/. acesso [27/12/2017].

CONSELHO NACIONAL DE EDUCAÇão. PORTUGAL (2011). Recomendação $n^{\circ}$ 5, 20 de out. 2011. Educação para o risco. Disponível em: http://www.cnedu.pt. Acesso em: [08/02/2017].

Faugéres, L. (1995). Risques naturels, risques urbains. Persee, França,v. 72, n. 2p. 111-120. Disponível em: http://www.persee.fr. Acesso em: [10/05/2016].

Ferreira A. B. R., Tarôco, L. T., Souza, C. J. O. (2016). A concepção do risco ambiental e sua abordagem na educação básica. Caderno de Geografia. Belo Horizonte: PUC-MG, v. 26, n.47, p. 615-62. DOI: $10.5752 /$ p.2318-2962.2016v26n47p522

Gauthier, C., Martineau, S., Desbiens, J. F., Malo, A., \& Simard, D. (1998). Por uma teoria da pedagogia: pesquisas contemporâneas sobre o saber docente. Ijuí: Unijuí, 17-37. 
Giroux, H. A. (2009). Praticando estudos culturais nas faculdades de educação. In: Silva, T. T. (org.) Alienígenas na sala de aula: uma introdução aos estudos culturais em educação. 8. ed. - Petrópolis, RJ: Vozes - (Coleção Estudos Culturais em Educação). p. 85 - 103.

Hewitt, K. (2014). Regions of Risk: A Geographical Introduction to Disasters. Routlege. 2. ed. New York, 410 p.

Hogan, D. J., Marandola Júnior, E. M. (2007). Vulnerabilidade a Perigos Naturais nos Estudos de População e Ambiente In: Hogan, D. J. (Org.). Dinâmica populacional e mudança ambiental: cenários para o desenvolvimento brasileiro.Campinas: Núcleo de Estudos de População-Nepo/Unicamp, p. 73-86.

Huberman, M. (1995). O ciclo de vida profissional dos professores. In: Nóvoa, A. (Org.). Vidas de professores. 2 ed. Portugal: Porto Editora, cap. II. p. 31-61.

Lourenço, L., Nunes, A., Gonçalves, A. B., Vieira, A., e Amaro, A. (2013). Fernando Rebelo, pioneiro e grande impulsionador do estudo dos Riscos em Portugal. Territorium, n. ${ }^{\circ}$ 20, 7-18.Disponível em: http://www.uc.pt/fluc/nicif/riscos/Documentacao/ Territorium/T20_artigos/T20_Artigo01.pdf. Acesso em: [08/02/2017].

Lourenço, L. (2015). Referencial de educação para o risco, uma recente publicação do Ministério da Educação e Ciência. Territorium, Portugal, n. ${ }^{\circ} 22$, p. 305-311. DOI: http://dx.doi.org/10.14195/1647-7723_22_25

Lourenço, L. (2006). Riscos naturais, antrópicos e mistos. Territorium, Portugal, n. ${ }^{\circ} 14$, p. 109-113. Disponível em: http://www.uc.pt/fluc/nicif/riscos/ Documentacao/Territorium/T14_artg/T14NNR01. pdf. Acesso em: [08/02/2017].

Marandola Júnior, E., Hogan, D. J. (2004). O Risco em perspectiva: tendências e abordagens. Geosul, Florianópolis, v. 19, p. 25-58 Disponível em: http:// morrodobau.ufsc.br. Acesso em: [16/03/2017].

Morandola Júnior, E. M., Silva, O. G. (2015). Diferentes percepções para a compreensão do conceito de risco no enfoque ambiental. Casa da Geografia de Sobral, Ceará, v. 17, n. 2, p. 12-22. Disponível em: http://uvanet.br/rcgs. Acesso em: [16/03/2017].

Nunes, L. H. (2009). Compreensões e ações frente aos padrões espaciais e temporais de riscos e desastres. Territorium, v. 16, p. 181-189. Dispnível em: http:// www.uc.pt/fluc/nicif/riscos/Documentacao/ Territorium/T16_artg/T16art18.pdf.

Souza, C. J. O. e de Oliveira, J. R. (2011). Representação de áreas de riscos sócio-ambientais: geomorfologia e ensino. Territorium, (18), 175-184. Disponível em: http://impactum-journals.uc.pt/territorium / article/view/3118/2370
ONU MARCO DE SENDAI. MARCO DE SENDAI PARA A REDUÇÃO DO RISCO DE DESASTRES 2015-2030. (2015). 25 p. Disponível em: http://www.unisdr.org. Acesso em: [16/03/2017].

ONU (2012). Rio + 20, Conferência das Nações Unidas sobre desenvolvimento sustentável. 0 futuro que queremos. 2012. 21 p. Disponível em: http://www. onu.org.br. Acesso em: [16/03/2017].

ONU/ISDR. (2009). Terminology on Disaster Risk Reduction, United Nations International Strategy for Disaster Reduction. Disponível em: https://www.unisdr.org/ we/inform/terminology. Acesso em: [16/06/2017].

PAC - PROGRAMA DE ACELERAÇÃO DO CRESCIMENTO - MINISTÉRIO DO PLANEJAMENTO (2012). Plano Nacional para prevenção de desastres naturais. Disponível em: http://www.pac.gov.br/noticia/c1619715. Acesso em: [27/12/2017].

Pimenta, S. G. (1996). Formação de Professores: Saberes da docência e identidade do professor. Faculdade de Educação, São Paulo, v. 22, n. 2, p. 72-89, 1996. Disponível em: http://www.revistas.usp.br. Acesso em: [16/03/2017].

Prudente, C. N. (2011). Estudo comparativo de metodologias para mapeamento das áreas de risco no estado de Minas Gerais (Dissertação (Mestrado em Geografia). Programa de Pós-graduação em Geografia - Tratamento da Informação Espacial, Pontifícia Universidade Católica de Minas Gerais, Belo Horizonte, 102 f. Disponível em: http://www. biblioteca.pucminas.br/teses/TratInfEspacial_ PrudenteCN_1.pdf. Acesso em: [15/02/2017].

Rebelo, F. (2010). Geografia física e riscos naturais. Coimbra: IU,215 p.

DOI: http://dx.doi.org/10.14195/978-989-26-0188-5

Rebelo, F. (2001). Riscos naturais e acção antrópica : estudos e reflexões. Coimbra: IU,274 p. DOI: http://dx.doi.org/10.14195/978-989-26-0467-1

Rufino, P. R., Souza, C. J. O., Pereira, G., Oliveira, M. S. (2016). Os tipos de riscos ambientais presentes nas mesorregiões Norte e Jequitinhonha de Minas Gerais no ano de 2015. In: II Simpósio Mineiro de Geografia:Geografia e contemporaneidades. Juiz de Fora, 2016. Disponível em: https://drive.google. com/file/d/0B015QFH-L4AxVIBxUkJ4RHFOLUk/view. Acesso em:[15/02/2017].

Saviani, D. (1996). Os saberes implicados na formação do educador. In: Bicudo, N. A. V.; Silva, J. C. A. (Org.). Formação do Educador: Dever do Estado, tarefa da Universidade. São Paulo: UNESP, p. 145155. Disponível em: https://pt.scribd.com. Acesso em: [16/07/2017]. 
Selby, D., Kagawa, F. (2012). Redução do Risco de Desastres no currículo escolar: estudo de casos de trinta países. Genebra: UNICEF, 218 p. Disponível em: http://www.unesdoc.unesco.org. Acesso em: [21/07/2016].

Silva, V. M. da (2017). Concepção de risco ambiental entre professores de geografia em Minas Gerais: conhecimentos e práticas em sala (Dissertação de mestrado em Geografia). São João del-Rei. Programa de Pós-Graduação em Geografia. Universidade Federal de São João del-Rei, 166p.

Smith, K. (2001). Environmental hazards: assessing risk and reducing disaster. 3 . ed. London: Routledge, $478 \mathrm{p}$.

Souza, L. B., Zanella, M. E. (2009). Percepções de Riscos Ambientais: Teoria e Aplicações. Fortaleza: Edições UFC, 240 p. Disponível em http://www.posgeografia.ufc.br. Acesso em: [16/03/2017].

Souza, C. J. O. (2013a). Riscos, Educação e Geografia. In: Riscos naturais, mistos e antrópicos. Livro de Homenagem ao Professor Doutor Fernando rebelo, Coimbra, Universidade de Coimbra, 174-194. Disponível em: http://www.uc.pt/fluc/depgeotur/publicacoes / Livros/livro_homenagem_FRebelo/127_142

Souza, C. J. O. (2013b). Área de risco socioambiental nas cidades: prática educativa na formação docente e na geografia escolar. VI Congresso Ibérico de Didática de Geografia (2013). Anais... VI Congresso Ibérico de Didática de Geografia Porto, Portugal.

Souza, C. J. O. (2014a). Educação para o risco: conhecimento e contribuição de professores de geografia para o tema risco ambiental em escolas públicas de Minas Gerais. Belo Horizonte, Projeto de Pesquisa submetido ao edital MCTI/CNPQ/Universal 14/2014 do Conselho Nacional de Desenvolvimento Científico e Tecnológico (CNPq).
Souza, C. J. O. (2014b). Educação geográfica e riscos socioambientais: experiências em atividades de extensão universitária. In: Multidimensão $e$ territórios de risco. 1. ed. Coimbra: Imprensa da Universidade de Coimbra, v. 1, p. 41-45.

DOI: http://dx.doi.org/10.14195/978-989-96253-3-4_6

Tardif, M. (2006). Saberes docentes e formação profissional. 17. ed. Petrópolis: Vozes,325 p.

Tardif, M., Lessard, C., Lahaye, L. (1991). Les enseignants des ordres d'enseignement primaire et secondaire face aux savoirs: Esquisse d'une problématique du savoir enseignant. Sociologie et sociétés,Canadá, v. 23, n. 1, p. 55-69. Disponível em: https://www.erudit.org. Acesso em: [21/04/2016].

Taroco, L. T., Ferreira, A. B. R., Souza, C. J. O. (2015). Geografia e educação para o risco: uma abordagem possível. Territorium Terram, v. 3, p. 49-53.

UNDRO. (1982). Office of the United Nations disaster relief coordinator in Genera. Shelter after disaster: Guidelines and assistance. New York: United Nations, 81 p. Disponível em: http://reliefweb.int. Acesso em: [21/07/2016].

Veyret, Y. (2007). Os riscos: O homem como agressor e vítima do meio ambiente. Tradução Dilson Ferreira da Cruz. 2. ed. São Paulo: Contexto, 320 p.

Veyret, Y., Richemond, N. M. (2007). O Risco, os riscos. In: Veyret, Yvette. Org.) Os Riscos - o Homem como agressor e vítima do meio ambiente. São Paulo: Contexto, p. 23-79.

Zabala, A. (2010). A prática educativa: Como ensinar. Tradução Ernani F. F. Rosa. Porto Alegre: Artmed, 224 p. 